\title{
Sensitization of the sphenopalatine ganglion (SPG) by periodontal inflammation: A possible etiology of sinusitis and headache in children
}

\author{
Haryono Utomo \\ Dental Clinic \\ Faculty of Dentistry Airlangga University \\ Surabaya - Indonesia
}

\begin{abstract}
Sinusitis is a frequent complication of allergic rhinitis. Theoretically, sinusitis could be found in human since infancy. The prevalence of diagnosed sinusitis is $20 \%$ of ambulatory patients in daily practice. Unfortunately, a lot of sinusitis cases must be treated by surgical operation. Other cases are treated conservatively with decongestants, corticosteroids, antibiotics and diathermy. However, dental treatment approach for sinusitis management is rarely discussed. Headache, especially migraine is also a common problem in children. Sinusitis and migraine, are closely related; sinusitis sufferers often accompanied by migraine and vice versa. This phenomenon resulting in misdiagnosis of the main etiology of sinusitis and migraine; if this case happens in young children, the diagnosis should be more complicated. Dental procedures which may directly reduce the periodontal inflammation were done to children diagnosed as sinusitis by otolaryngologist and pediatrician. In a short period of time, the sinusitis and headache symptoms subsided. The objective of this case reports is to propose the possible explanation of the neurogenic switching mechanism cut off, that resulting in the instant relief of sinusitis and headache symptoms. Regarding the immediate relief of the symptoms, the role of autonomic nervous system should also be considered. Since parasympathetic innervations of nasal, sinus mucosa and maxillary periodontal tissues originated from the sphenopalatine ganglion; the conclusion is that the periodontal inflammation may sensitize the sphenopalatine ganglion which may trigger sinusitis and headache in children.
\end{abstract}

Key words: sphenopalatine ganglion, periodontal inflammation, sinusitis, headache

Correspondence: Haryono Utomo, c/o: Fakultas Kedokteran Gigi Universitas Airlangga. Jln. Mayjend. Prof. Dr. Moestopo No. 47 Surabaya 60132, Indonesia. E-mail: dhoetomo@indo.net.id. Telp. +6231 5053195.

\section{INTRODUCTION}

Sinusitis is an inflammation involving the mucous membrane of one or more paranasal sinuses, accompanied by symptoms i.e. nasal congestion, facial pain; and thick and purulent nasal discharge. It is a relative common problem in daily practice; in the USA (1995), 13.4-25 million visits to medical practice were related to sinusitis and/or their subsequent effects. ${ }^{1}$

Most sinusitis are caused by viral infection, and recovered without antibiotic therapy, ${ }^{1}$ which is coincident to reported studies that a proportion of sinusitis patients had a negative culture. ${ }^{2}$ Conservative treatments of sinusitis include decongestants, corticosteroids, antibiotics and diathermy. If conservative treatments failed; surgical procedures had to be done to treat sinusitis. ${ }^{1}$ Unfortunately, dental treatment procedure is not included in the conservative treatment of sinusitis.

The most common headache in children is migraine without aura. It may not be hemicranial in children and is less intense compared with the migraine in adults. ${ }^{2,3}$

Parasympathetic activation, ${ }^{4}$ as well as the hypothesized mechanism of neurogenic or immunogenic switching (i.e. crossover interactions of neurogenic and immunogenic inflammation), may account for both the frequent occurrence of nasal symptoms in migraine; and the possibility that sinus inflammation can sometimes act as migraine trigger. ${ }^{3}$

The sphenopalatine ganglion (SPG) is related to the autonomic nervous system; the parasympathetic and sympathetic nerves. Stimulation of the parasympathetic nerves lead to nasal congestion which also called "stuffy nose".

Recently, the role of SPG as a treatment target of rhinitis, sinusitis or migraine symptoms; such as blocking the SPG with injections, 5,6 or nasal spray forms, had been popularized. ${ }^{6}$ However, the role of dental and periodontal inflammation in SPG sensitization is rarely discussed.

Previous case reports which related to headache ${ }^{7}$ and allergic rhinitis in children, 8,9 revealed the possibility of oral inflammation as a trigger of headache and rhinitis. Nevertheless, the proposed mechanism limited only by immunological mechanism; the possibility of neurogenic mechanism involvement was not apparently discussed.

The objective of this case report is to propose a new concept in propagation of oral inflammation through the 
neurogenic switching mechanism involving the periodontal tissues. Sensitization of the SPG by periodontal inflammation may induced rhinitis, sinusitis and headache.

\section{CASES}

Case 1: A 7 years old boy, suffering from sinusitis and diagnosed as maxillary sinusitis by an otolaryngologist, came to a private dental practice. At that time he had already suffered for more than 3 years. When he was 4 years old, he had already treated by another otolaryngologist. The diagnostic of maxillary sinusitis was confirmed with Water's projection radiograph.

Treatment which done by the first otolaryngologist, was medication and diathermy for more than 10 times. The result was insignificant, he still suffered from sinusitis symptoms including headache. He also became temperamental and had an impaired hearing which caused speaking difficulty of some consonants sound, especially "s".

Approximately three years later, he consulted another otolaryngologist and was also diagnosed as sinusitis, which confirmed by Water's projection radiograph. At that time, he was also given medication and diathermy for 10 times.

These treatments gave satisfying results, most of the symptoms disappeared. However, when the weather was humid, the severe symptoms reappeared. He was also told to study music to improve his impaired hearing, and he had done his best in music playing, especially the violin.

Extraorally, the patient appeared fatigue, and there was a small amount of thin nasal discharge in the nostrils. Intraoral inspection showed moderate dental plaque in every region, abundant dental plaque was seen in the upper posterior regions. Inflamed gingival was also seen in several regions, especially the 1655 and 65 26, on which pseudopockets were detected and contained impacted food. The patient had no caries or filling.

Case 2: A 7 years old girl, came to a private dental practice as an orthodontic patient. At that time, she had already suffered from sinusitis for about 3 years as diagnosed by an otolaryngologist and a general practitioner. The diagnosed was confirmed with Water's Projection radiograph.

She had been treated with a lot of medications, and diathermy for more than 40 times without significant improvement. Her mother said that the latest medications given by a general practitioner were helpful, but if it were stopped the symptoms recurred.

Extraorally, the patient looked normal, except a small amount of watery discharge came out from her nostrils. Intraoral inspection showed moderate dental plaque in every region. Inflamed gingival also seen in several regions, especially the 1655 , on which pseudopocket was detected. The patient had no caries or filling.

\section{CASE MANAGEMENT}

Oral plaque control therapy was done with rotating brush, pumice and contra-angled handpiece. The interdental spaces were irrigated with hexetidine $0.1 \%$; after about 1 minute, the interdental spaces and pseudopockets were searched for food remnants or debris using a sickle shaped explorer. Dark red blood oozed from the interdental spaces and pseudopockets, especially in the upper left and right posterior teeth.

Approximately one minute later, the patients could breathe easily through his/her nostrils. The parents said that before the dental procedures, despite many medications and diathermy, the patients could not breathe easily through the nose.

The patients and their parents were taught how to conduct oral plaque control procedures and were prescribed hexetidine $0.1 \%$ mouthwash. The patients were scheduled for another visit in a week time.

On the second visit; extraorally, the patients looked more cheerful. The parents said that all the symptoms related to sinusitis (i.e. nasal congestion, headache) had already disappeared, they only had watery (thin) discharge.

Especially in the first case, watery discharge was found came out from the right nostril; the intraoral inspection coincidentally found that the gingiva in the buccal area of 1655 was still inflamed and bleed easily. The interdental and pseudopockets exploration procedures were done until dark red blood did not oozed anymore.

In the second case, intraorally, the gingiva had regained its normal color and consistency; and the sinusitis symptoms were disappeared. The latest evaluations were in April 2006, 6 months after the first case and 2 years after the second case management. Severe sinusitis symptoms did not exist, only occasional sneezing and rhinorrhea.

\section{DISCUSSION}

Sinusitis may affect everyone since infancy, since the maxillary sinuses have already developed in the third month of fetal life, followed by the ethmoid sinuses. ${ }^{1}$ As sinusitis mostly accompanied by migraine or vice versa, ${ }^{3}$ diagnosis of the main etiology could be difficult . Consequently, it will become more difficult if happen to infants or young children.

There are several symptoms which resulting in misdiagnosis of sinusitis and migraine. The migraine symptoms are facial pain, facial flushing, lacrimation, rhinorrhea, nasal congestion and vertigo, ${ }^{10}$ whereas sinusitis symptoms are nasal congestion, facial pain, malaise ${ }^{2}$ and thick and purulent nasal discharge..$^{3,4}$ In addition, several mechanisms were also proposed related to the interrelationship between sinusitis and migraine, that are: autonomic symptoms caused by parasympathetic cranial 
activation, ${ }^{10}$ and neurogenic and immunogenic switching mechanism. ${ }^{3}$

While acute sinusitis is widely accepted and recognized as a cause of headache, chronic sinusitis or sinonasal abnormalities as a cause of headache has been more controversial. Chronic sinusitis is not validated as a cause of headache unless relapsing into an acute phase. ${ }^{4}$

Migraine and tension-type headache are often confused with true sinus headache because of "similarity in location". ${ }^{4}$ On the other hand, migraine may cause autonomic symptoms mimicking sinus problem (i.e. nasal congestion and rhinorrhea) is proposed through the cranial parasympathetic activation by sensitized trigeminal nucleus caudalis (Figure 1). ${ }^{10}$

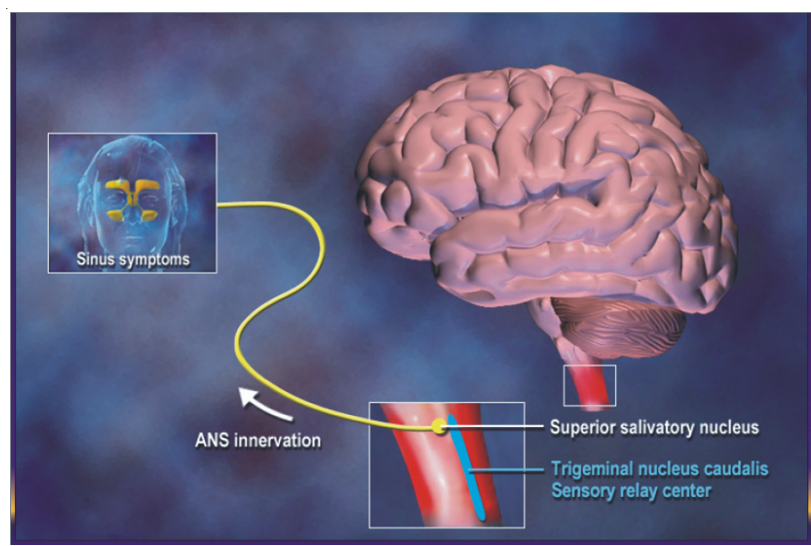

Figure 1. Autonomic symptoms by cranial parasympathetic activation in migraine. ${ }^{10}$

Pain in migraine is believed elicited by the activation of trigeminovascular structures which manifests as headache. ${ }^{4}$ Nevertheless, the pathogenesis of pain in migraine was not completely understood, but three factors merit consideration: 1) the cranial blood vessels, 2) the trigeminal innervation of vessel, and 3) the reflex connection of the trigeminal system with the cranial parasympathetic outflow. ${ }^{11}$

Nasal congestion is the most common symptom in sinusitis, which associated with turbinate dysfunction. The etiology of turbinate dysfunction is multifactorial. Because the turbinate have a very rich blood supply and are governed by the parasympathetic nervous system, anything that affects either of these 2 systems affects the turbinates and hence, the nose. ${ }^{12}$

The autonomic nervous system provides the general innervation to the nose, with the parasympathetic nerves supplying the resting tone and controlling secretions. The nerve supply originates from the N VII (facial nerve) at the inferior salivatory nucleus and follows along the distribution of the N VII through the SPG. ${ }^{12}$

According to Cady and Schreiber, the connection between sinusitis and migraine should be related to the neurogenic and immunogenic switching hypothesis. ${ }^{3}$ This hypothesis consists of the crossover mechanism between immunogenic and neurogenic inflammation. . $^{3,13}$

Neurogenic and immunogenic switching can be explained as follows: afferent sensory nerve fibers can be stimulated by histamine and tryptase from degranulated mast cell, proinflammatory cytokines secreted from LPS stimulated macrophages, bradykinin, and nitric oxide (NO). Subsequently, stimulated afferent nerve fibers release neuropeptides that are substance $\mathrm{P}$ (SP) and calcitonin generelated peptide (CGRP) which in turn stimulate mast cells. ${ }^{13}$

Mast cells degranulation induced by antigens, bacteria, proteoglycans, LPS, chemokines, and physical factors (i.e. cold temperatures, ultraviolet $\mathrm{B}$ radiation, exercise). ${ }^{14}$ These neurogenic switching mechanism is a vicious circle until something "cut off" the process.

Considering the connection of sinusitis and migraine, much attention has been given to the sinuses and nose as a source of acute and chronic head and face pain. It is therefore worth a brief review of sinonasal innervation. The general sensory innervation of the mucosa of the nose and paranasal sinuses is from the ophthalmic (V1) and maxillary branches (V2) of the trigeminal nerve, with minor contributions from the greater superficial petrosal branch of the N VII (facial nerve) (Figure 2). ${ }^{4,15}$

Some researches found that sensitization of the SPG had already proposed to trigger rhinitis, sinusitis, asthma, headache and other ailments. It maybe related to the anatomical characteristics of SPG which contains sensory, parasympathetic and sympathetic nerves. ${ }^{5,15}$

Sagittal dissection illustration of the nose and its adjacent tissues shows the parasympathetic innervations of nasal mucosa and sinus passages by the SPG (Figure 2). ${ }^{15}$ The SPG has sensory innervation by V2 which connected by fine fibers; and the sphenopalatine nerve. The collaterals of V2 are able to store SP in the ganglion. ${ }^{5}$

The parasympathetic nerves originated from the vagus nerve and the superior cervicalis ganglion. It has either a secreto-motor function to the nasal and sinuses, or soft and hard palate. ${ }^{5}$

Activation of the SPG by V2 which releases neuropeptides (i.e.SP, CGRP) may cause the inflammation of the neighboring artery and mucosa. Inflamed nasal mucosa resulting in nasal congestion, sinusitis; and migraine. ${ }^{16}$

Maxillary periodontal tissues are innervated by the sensory nerve fibers through the V2; the parasympathetic nerve fibers through the SPG, and sympathetic nerve fibers through the superior cervical ganglion. ${ }^{13}$ From this point of view, it seems possible that oral inflammation which involving the periodontal tissues, in some instances could elicit sinusitis and migraine.

The correlation between the SPG, sinusitis and migraine also proved by blocking the SPG with xylocaine and cortisone-type injections to relieve allergic rhinitis and sinusitis, ${ }^{5,6}$ injection could be done through the greater palatine foramen. The others are nasal applicator/ transnasal 


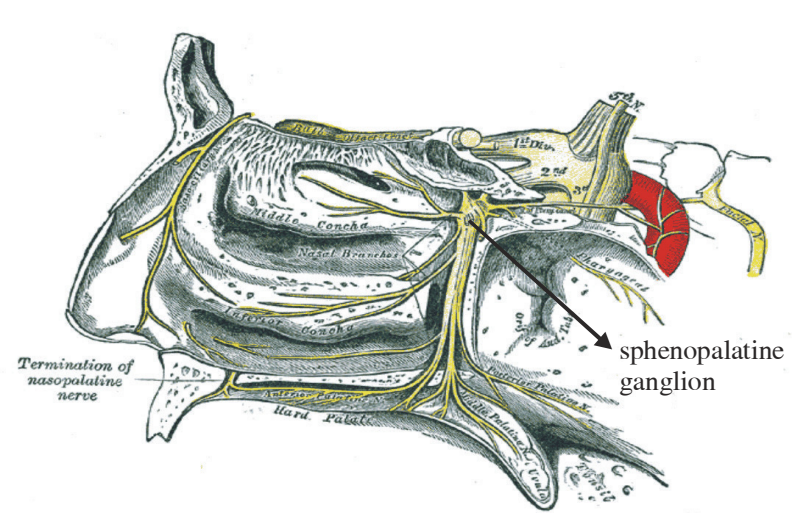

Figure 2. Sagittal dissection of the nose. ${ }^{15}$

approach of medicaments (i.e. essential oil), ${ }^{5}$ or the application of nasal spray forms of naratriptan (antimigraine). ${ }^{4}$

The possible correlation of oral inflammation and allergic rhinitis which caused by dental plaque had been discussed in several literatures. ${ }^{8,9}$ Since rhinitis, sinusitis and migraine related mostly to the neurogenic and immunogenic switching mechanism; the oral plaque control therapy which mostly related to the immunogenic inflammation should take several hours to give a significant effect.

A plausible explanation to this mechanism was that after the sudden fall of bacteria population; the available immune response could by itself reduces the inflammation by gradually eliminate the infectious agents, neutralizes the toxins and secretes anti-inflammatory mediators. Subsequently, the resolution of immunogenic inflammation also reduced the neurogenic inflammation.

In this case report, the patients were selected as caries free and had no filling. It was meant to exclude the interference of pulpal inflammation which may also triggers the V2 afferent sensory nerves. This study was limited only on the possibility of mucosal and periodontal sensory or parasympathetical nerves induction to the SPG, which acted through the neurogenic switching mechanism.

Instant relief of the symptoms (i.e. reduced nasal congestion and headache) that only took several minutes to give a significant effect is proposed to be the "assisted drainage" procedure to the chronic inflamed tissues. Blood which oozed after the exploration of the pseudopockets using sickle-shaped explorer should contained bacteria, toxins (proteoglycans, PGN and lipopolysaccharides, LPS), pro-inflammatory mediators and enzymes, ${ }^{17}$ which may induced neurogenic inflammation of the maxillary nerve (V2) or the parasympathetic nerves of maxillary periodontal tissues.

Rapid decrease of toxins and pro-inflammatory mediators level may cause instant resolution of inflammation, ${ }^{18}$ and the neurogenic switching mechanism "cut off". It may indirectly diminish the sensitization the parasympathetic nerves of the SPG by V2, or directly from the sensitized maxillary periodontal parasympathetic nerve fibers, thus decreasing the nasal congestion and migraine. The remarkable result of treatment procedures in this case report was similar with the previous article about headache in children. ${ }^{7}$

This "assisted drainage" is a simple and effective procedure in sinusitis and headache management in children, which are suspected to be induced by periodontal inflammation. In order to minimize unnecessary or prolonged treatments and medications for the sinusitis and headache in children; the collaboration of general practitioners, otolaryngologist, paediatrician and dental practitioners is important.

Continuing dental health maintenance by proper brushing, using mouthrinses and flossing should be taught to the patients and their parents for obtaining maximal results. Regular dental check-up should be done to maintain optimum oral health.

The sphenopalatine ganglion is the target of recent sinusitis and migraine treatments. Concerning to the direct effect of "assisted drainage" of the chronic inflamed pseudopockets, which resulted in the immediate disappearing of sinusitis and headache symptoms; it is concluded that periodontal inflammation is able to sensitize the SPG which eventually may elicit sinusitis and headache.

\section{REFERENCES}

1. Widodo AK. Rinosinusitis: etiologi dan patofisiologi. Pendidikan berkelanjutan IV Ilmu Kesehatan Telinga Hidung Tenggorok. 1-3.

2. Behrman RE, Kliegman RM, Jenson HB. Nelson textbook of pediatrics. 17th ed. Philadelphia: Saunders; 2004. p. 760, 1832.

3. Cady RK, Schreiber CP. Sinus headache or migraine. Neurology 2002; 58:S10-4.

4. Stroud RH, Bailey BJ, Quinn FB. Headache and facial pain. Dr. Quinn's online textbook of otolaryngology grand rounds archive. 2001. Available online at URL. http://www.utmb.edu/otoref/Grnds/ HA-facial-pain-2001-0131/HA-facial-pain-2001. doc. Accessed March 20, 2006.

5. Klinghardt DK. The Sphenopalatine ganglion (SPG) and environmental sensitivity. Lecture on $23^{\text {rd }}$ Annual International Symposium on Man and his Environment. June 9-12, 2005. Dallas Texas.

6. Mirkin G. Chronic stuffy nose, nasal polyps and fungus. Available inline at URL http://www. drmirkin.com. Accessed April 15, 2006.

7. Pradopo S, Utomo H. Nyeri kepala pada anak.. Majalah Kedokteran Gigi (Dent J) 2005; Edisi Khusus Pertemuan Ilmiah Nasional Ilmu Kedokteran Gigi Anak I: 60-66.

8. Utomo H, Soehardjo I. Hubungan respons imun dan kesehatan rongga mulut dengan rinitis alergika pada anak. Majalah Kedokteran Gigi (Dent J) 2005; Edisi Khusus TIMNAS IV:69-76.

9. Utomo H, Setijanto D. Apakah terapi pengendalian plak gigi dapat menurunkan keparahan rinitis alergika pada anak. Majalah Kedokteran Gigi (dent J) 2005; 38(2):96-102.

10. Green MW. Diagnosing and treating migraine: low tech diagnosis, high tech treatment. Available online at URL http://www.amaassn.org/ama1/pub/ upload/ mm/31/24pres-green.pdf. Accessed February 20, 2006.

11. Goadsby PJ, Lipton RB, Ferrari MD. Migraine-current understanding and treatment. N Eng J Med 2002; 346(4):257-70.

12. Archer SM. Turbinate dysfunction. Emedicine. cm/ent/ RECONSTRUCTIVE-SV. Accessed April 10, 2006. 
13. Lundy W, Linden R. Neuropeptides and neurogenic mechanism in oral and periodontal inflammation. Crit Rev Oral Biol 2004; 15(2):82-98.

14. Walsh LJ. Mast cells and oral inflammation. Crit Rev Oral Biol Med 2003; 14(3):188-98.

15. Gray's Anatomy of the human body. The trigeminal nerve. Available online at URL. http://education.yahoo.com/reference/gray. Accessed March 15, 2006
16. Boyd J. Pathophysiology of migraine and rationale for a targeted approach and prevention. Available online at URL http:// www.migraineprevention.com/index/html. Accessed February 15, 2006.

17. Li XJ, Kolltveit KM, Tronstad L, Olsen I. Systemic diseases caused by oral infection. Clin Microb Rev 2000; 13(4):547-58.

18. Rabson A, Roitt IM, Delves PJ. Really essential medical immunology. $2^{\text {nd }}$ ed. Oxford: Blackwell pub; 2005. p. 91, 116-7. 